\title{
EL ELEMENTO MUSICAL EN LA OBRA DE RENÉE FERRER
}

\author{
MARIA GABRIELLA DIONISI
}

1

Ferrer R., Las cruces del olvido, Asunción, Intercontinental, 2001, p. 9.
Al analizar la obra de Renée Ferrer, que se compone de diecisiete poemarios, dos novelas, cinco colecciones de cuentos, algunas de las cuales para niños, y una pieza teatral, nos damos cuenta de su gran vitalidad creativa, de su capacidad de expresarse utilizando diferentes géneros literarios.

Perteneciente a la llamada generación del $' 60$, nuestra autora ha contribuido con su quehacer literario a la renovación de la literatura paraguaya, a través del uso de temáticas y técnicas innovadoras.

La poesía es, sin duda, el campo en el que ha dado pruebas fehacientes de sus capacidades artísticas. En efecto, todo su trabajo poético está impregnado de una gran libertad imaginativa $y$, al mismo tiempo, de un profundo sentido de la palabra concreta en la descripción despiadada de la realidad que la rodea.

Ella misma, en la «Presentación» de su último libro, Las cruces del olvido, evidencia esta actitud al afirmar que «el poeta escribe sobre aquello que sacude hasta la raíz sus fibras más recónditas. El amor, la muerte, el tiempo, la soledad son temas inevitablemente frecuentados, a través de los cuales explora su propia emoción o ingresa al territorio de los grandes interrogantes; sin embargo, no es extraño que trascienda su interioridad para mirar a los otros, asumiendo como propia la desdicha o la dicha de los demás, actuando como caja de resonancia del drama humano, con sus atroces o sublimes consecuencias» ${ }^{1}$.

De hecho, su poética, caracterizada por la musicalidad y la armonía, tiende a la construcción de un cosmos luminoso y obscuro al mismo tiempo, en el que brilla altiva la muer- te. Todos los elementos de la naturaleza, el mar, los árboles, los pájaros, confluyen en una sola voz cuyo timbre refleja la seducción de los sentidos, el abandono total de la mujer, la libertad del erotismo que amplía las vibraciones de su corazón para luchar contra el tiempo que pasa.

De la misma manera, los temas sociales, el conflictivo marco histórico del que forma parte, penetran en este universo buscando en la palabra su posible salvación.

En Desde el Cañadón de la memoria de 1984, dolorosa y vibrante conmemoración de los caídos de la guerra de 1932 y simbólica continuación del poemario Los treinta mil ausentes: elegía a los caídos del Chaco de Josefina Plá, así como en Las cruces del olvido de 2001, escrito "en el nombre del 'marzo paraguayo», Ferrer trata de fijar en la página el dolor colectivo de la ausencia, de levantar su voz contra la ignominia de una guerra fraticida y de la crueldad de todos «los fariseos - banderillas indómitas en el lomo del Mal»².

Además, su compromiso por transformar en pura poesía las emociones, las congojas y los sinsabores personales, a partir del primer poemario, Hay surcos que no se llenan de 1965, ha engendrado una búsqueda continua de nuevas formas estilísticas.

Pasando del verso libre al soneto tradicional, del uso abundante de la metáfora y del símbolo al crudo realismo, Renée Ferrer logra sumergirnos en un universo complejo y multifacético en el que conviven erotismo, sensualidad, relámpagos de felicidad y amarga tristeza, horror por un mundo envilecido por el abuso y la perversión. 
Un universo en el que a veces la palabra se diluye en imágenes livianas, mientras que en otras nos atrae hacia el abismo insondable de un mundo en progresiva decadencia.

Dicha exploración de las nuevas posibilidades que ofrecen los instrumentos estilísticos tradicionales le lleva a experimentar una fusión entre la música y la narración: jugando con las palabras, Ferrer captura los ambientes, las vibraciones de la primera y las incluye en la segunda.

De esta manera nace, en 1987 , el poemario Nocturnos en el que la búsqueda constante de la palabra precisa del verso rítmico, se enriquece de la perfección compositiva e interpretativa del elemento musical concreto.

El libro, compuesto por trece poesías, agrupadas en cuatro trípticos, más una poesía suelta, tiene como temas principales, como se nota leyendo los mismos títulos, el amor, la maternidad, el tiempo, los enigmas de nuestro mundo contemporáneo.

Los argumentos forman parte de la poética ferreriana pero la novedad estriba en el acompañamiento musical que la autora da a los textos, puesto que cada uno de ellos está relacionado con un Nocturno del gran «poeta del piano», Fryderyk Chopin.

En efecto, para cada poesía, como epígrafe, Ferrer indica el número del Nocturno elegido, invitando al lector a recordar la melodía y a seguir el ritmo durante la lectura de los poemas.

En el «Prólogo» al libro, ella misma declara: «mi intención fue escribir poemas cuyos versos se correspondieran con las frases musicales, el ritmo y los silencios de los Nocturnos de Chopin, logrando una unidad total entre el sonido y la palabra, sin que ellos ultrajasen la música, ni la utilizaran como apoyatura». Pero, al darse cuenta de que el intento habría sido no sólo «imposible sino inauténtico», ella opta «por descifrar el eco de su música [...] expresando angustias existenciales mías y una concepción del mundo, de la vida y de la muerte» ${ }^{3}$.

Pero, ¿ ¿por qué elegir a Chopin? Probablemente porque, como ya en 1841 escribió Robert Schumann en uno de sus estudios críticos, así como «egli disse ch'era stato ispirato per le sue ballate da alcune poesie di Mickievicz", al mismo modo "un poeta potrebbe trovare molto facilmente le parole dalla sua musica; essa commuove nel più profondo dell'anima» ${ }^{4}$.

La emoción que emana de su música y que es la transformación pura y perfecta de su mundo interior en un lenguaje musical, atrae a Renée Ferrer, involucrándola y empujándola a la expresión libre de sus más íntimos pensamientos. Así como sucede en los Nocturnos de Chopin, a veces la armonía de sus poemas es intensamente dolorosa, otras nostálgicamente suave. Saltos de fuerza apasionada se alternan a voluptuosos abandonos, a desahogos líricos, a juegos infantiles e imprevisibles, a abruptas imágenes de vidas sin salida:

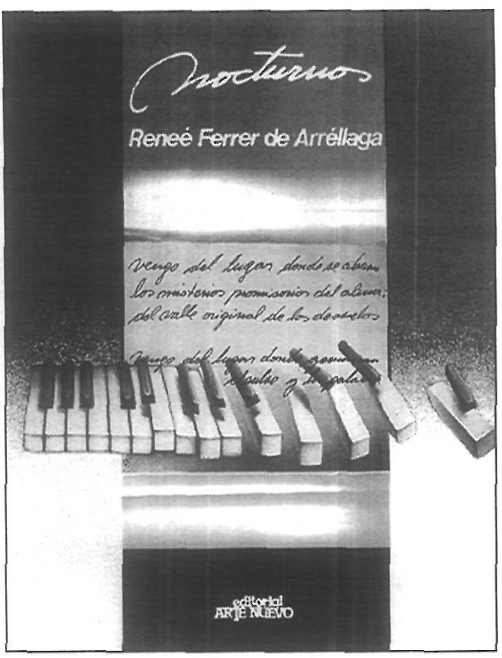

Portada de Nocturnos.

En las islas del tiempo llora el hombre cegado por fogatas innombrables; bajo sus venas palpitantes brota el frío manantial de las congojas. $[\ldots]$

Llegará

$$
\begin{aligned}
& \text { a la luz, } \\
& \text { sin agobio, } \\
& \text { sin odio, } \\
& \text { plenamente? }
\end{aligned}
$$

También la gráfica de los poemas está relacionada con la música. En una reciente entrevista nos explicó la técnica con la que elaboró su trabajo, afirmando que «los versos largos que se caen de los renglones, son como las frases musicales que se van desgranando en los Nocturnos. Busqué palabras con vocales graves para representar los sonidos graves, palabras con vocales suaves para los sonidos agudos y pianísimos. Antes de empezar a escribir los poemas hice gráficas de cada uno de ellos con rayas más gruesas o muy finas para significar los sonidos, espirales para significar los pianísimos, espirales más fuertes o menos pintadas según el sonido de esos pianísimos, y eso fue lo que traté de pasar a las palabras»6.

Sólo en la última poesía el ritmo cambia. La necesidad de representar un acontecimiento histórico, como el encuentro-choque entre árabes y españoles, lleva a Ferrer a inspirarse para sus versos en la música de Enrique Granados, el gran compositor español, admirador de Chopin y expresión del espíritu de su propia tierra.
3 Ferrer R., Nocturnos, Asunción, Arte Nuevo, 1987, p. 9.

4 Schumann R., La musica romantica, Torino, Einaudi, 1982, p. 192.

5 Ferrer R., "Angustia», en Nocturnos, cit., pp. 87-89.

6

Entrevista inédita con Renée Ferrer, febrero 2002.
El elemento musical en la obra de Renée Ferrer

MARÍA GABRIELLA DIONISI 


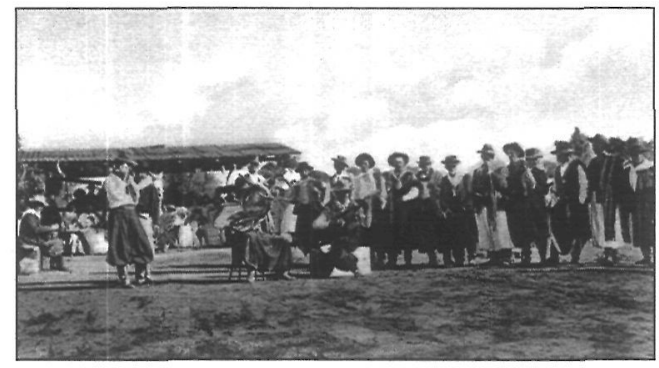

Fiesta de 1910. (Foro: Archivo de Jorge Rubbiani).
En «Quejas o La Maja y el Ruiseñor», cuyo título recupera el de uno de los cuadros de Goyescas de Granados, los versos nacen como homenaje y representación alegórica de la conquista de España por parte de los árabes y de su posterior abandono. Pero, al mismo tiem7 Ferrer R., "Quejas, o la Maja y el Ruiseñor», en Nocturnos, cit., p. 115.

8

Idem.

9

Ferrer R., «Tiempo», en ibídem, p. 71.

10

Ferrer R., Los nudos del silencio, Asunción, Arandurâ, 2000, p. 80.

11

Ibídem, p. 204.

12

Ibidem, p. 152.

13

Ibídem, p. 14.

14

Ibidem, p. 17.
El elemento musical en la obra de Renée Ferrer

MARÍA GABRIELLA DIONISI po, constituyen el canto apasionado y melancólico de «los majos enamorados» del músico español, que en Ferrer se convierte en el recuerdo amargo y triste de su pasado amor.

La doncella (España) a veces evoca imágenes sensuales en el furor de los encuentros, otras su nostalgia rememora la paz conquistada cuando «tu congoja ancestral / se consoló con mis besos» ${ }^{7}$.

En el final, la voz del ruiseñor (el árabe) se diluye en un último susurro, convencido de que

...en ti cantará,

hasta que muera el tiempo,

la diadema de agua

que te ceñí en la frente ${ }^{8}$.

De tal manera, Nocturnos es el libro de la añoranza, del tiempo que huye y cuyo

... paso es un enigma

que perdura y se obstina en cada flor del universo ${ }^{9}$

y es el libro también de la búsqueda de la armonía a través de la musicalidad de la palabra y de las melodías de Chopin.

Por el contrario, la novela Los nudos del silencio, publicada en 1988, es la representación del papel psico-terapéutico, liberatorio de la música y sobre todo de su valor de medio de comunicación entre los seres humanos porque, como afirma una de las protagonistas, «la palabra no es ciertamente el único vehículo del conocimiento» ${ }^{10}$.

En el texto ya no queda rastro de románticas nostalgias ni de cósmicas consideraciones sobre el destino del hombre, sólo encontramos el despiadado autoanálisis de dos mujeres cuya vida se encuentra estrechamente vinculada durante una hora o poco más.
Estamos ante un tiempo cronológico mínimo pero que se dilata al máximo, por ser el tiempo de la memoria que nos revela un pasado próximo y remoto, desalentador y conflictivo.

A través de un monólogo interior alternado, las dos protagonistas, Malena y Mei Li, diferentes «hasta el abismo en circustancias», iguales «hasta el absurdo en la congoja» ${ }^{11}$, animadas por la música de un saxo que «se interna como un dedo agudo en los intersticios recónditos del ser» ${ }^{12}$, tratan de reordenar el desorden de sus vidas, de sacar a la luz un mundo aún no expresado.

Su encuentro es fruto de una casualidad, de un «fatal error» del protagonista masculino, Manuel que, al llegar a París, «la ciudad donde germinan como hongos los placeres» ${ }^{13}$, decide ir con su mujer, Malena, a un espectáculo de streap-tease.

Lo que va a ocurrir en las horas siguientes ya no está bajo su control, como hasta aquel momento siempre había sucedido en su vida de hombre acostumbrado a mandar dentro y fuera de casa. Todo a su alrededor preanuncia un desenlace catastrófico para él, catártico para su mujer, hasta aquel momento víctima silenciosa de una sociedad machista de la que Manuel representa el perfecto prototipo.

La misma ciudad, perdida su imagen tradicional de capital del amor como diversión galante, fascinante juego sentimental compartido, los acoge entre tinieblas. Ellos, «empalidecidos por unos faroles mortecinos ${ }^{14}$, tan en contraste con las luces características de la Ville-Lumière de la Belle Epoque descrita por autores como Alberto Blest Gana o Eugenio Cambaceres, se tumban en una sala envuelta en una «sórdida niebla artificial», donde se está representando un porno-show lesbiano, protagonizado por una bailarina oriental.

Es como entrar en un túnel sin salida, bajar a los infiernos, allá donde las voces se elevan para llorar sus penas, para confesar y expiar sus culpas.

La estructura polifónica de la novela se halla ahora ante su máximo desenlace; cada personaje cuenta su propria historia, hasta escudriñar los más obscuros recovecos de sus ánimas.

Así como ya notó David Foster al reseñar la novela y como nos confirmó la misma autora, destacando su atracción por la precisión matemática de la música de Johann Sebastian 
Bach, Los nudos del silencio se basa sobre la forma musical de la fuga del gran compositor alemán.

En la planificación de la novela, se pueden vislumbrar los elementos peculiares de la fuga: la contraposición de diferentes voces (soprano, contralto, bajo, a las que a veces se añaden otras más), cada una con su propria individualidad y la presencia de dos momentos fundamentales (la exposición y el episodio) que se alternan continuamente.

De hecho, aquí también nos encontramos con tres voces narrativas (Malena, Manuel, Mei $\mathrm{Li}$ ), a las que se suma un autor omnisciente y el personaje eje de la narración: el saxo. Todos ellos, a niveles y con tonalidades diferentes, expresan el tema principal, la condición de humillación y discriminación de la mujer de cualquier clase social y nacionalidad.

A éste se le añaden episodios diferentes, acontecimientos de sus propias vidas, recuerdos de miserias y de sórdidas claudicaciones que tratan de explicar las razones del profundo malestar que los oprime.

Además, tenemos lo que se define en campo musical el «controsoggetto», que recuerda el tema principal, ya que es su imagen reflejada. En la novela, éste se reconoce en la presencia de otro tema, la denuncia del poder dictadorial del que Manuel es digno representante, al ser «una discreta pieza en el engranaje de un sistema corrupto que nos envilece por mutuo consentimento» ${ }^{15}$.

De tal manera, nos damos cuenta de que esta estructura satisface una necesidad fundamental de Renée Ferrer ya que, como ella nos explicó, «en mi literatura siempre me ha interesado la participación de diferentes voces, ya sea comunicándose entre sí o como vías posibles hacia el conocimiento humano. Yo creo que no existe «una» verdad, así como no existe «una» voz que tenga el privilegio de ser la única e indiscutible. Todas las voces tienen su cosmovisión, su criterio sobre la vida y las cosas, los sentimientos y las actitudes» ${ }^{16}$.

Y son éstas las voces que dan vida a la novela. Voces raras ya que no tienen sonido, voces atragantadas, atrapadas por los nudos de un silencio que les convierte a todos «en cómplices ominosos del cualquier acto ${ }^{17}$. Pero, en algunos casos, el silencio puede transformarse en un lenguaje de solidaridad, puesto que, como afirma Delgado Costa, «es precisamente a través de ese silencio solidario que tanto
Malena como Mei Li describen, identifican y logran romper los nudos que las atan» ${ }^{18}$.

Sólo una voz se oye concretamente en la sala, que «flota dentro de una esfera de música»" ${ }^{19}$ es la del saxofón que cuenta y habla sustituyéndose a las palabras mudas de las protagonistas.

Tenemos que partir de la elección de este instrumento musical para comprender el sentido más profundo de la novela, puesto que el saxofón no es un simple elemento estructural, sino que representa, más bien, otro personaje que actúa autónomamente y que, a lo largo de toda la narración, muerde, corta, acuchilla «el aire con su filo sonoro» ${ }^{20}$, llora, se aduerme, calla, gime, porque «el sonido del saxo no es sonido: es carne y es sollozo y es latido» ${ }^{21}$.

Su misma melodía le atribuye este carácter humano ya que «va arrastrando por imprevistos pasajes su alegría de metal, cayendo después en la congoja; tal cual la vida, que salta desde el más absurdo desenfreno al apaciguamiento entregado de la tristeza. Se deja ir de tono en tono, obstinándose en uno, precipitándose en otro, para deslizarse hasta la pausa, perdurando dentro de un laberinto que sólo el bronce de su garganta consiente»22.

Se convierte en elemento simbólico, no tanto por la evidente similitud entre las palabras saxo/sexo o por la posible identificación entre la forma del instrumento y la del falo, sino por su propio carácter musical, por el tipo de ritmo al que está relacionado, por ser el instrumento ideal del jazz.

Si nos referimos a los orígenes de los elementos característicos del jazz, como expresión de un mundo de hombres explotados, humillados, como expresión lírica de la soledad y de la marginación, nos damos cuenta inmediatamente de la directa correspondencia entre esta música y el tema de Los nudos del silencio.

Además, por lo que atañe a su aspecto formal, tenemos una relación estrecha entre este tipo de música y la estructura de la novela. En efecto, el jazz, nacido de la unión de spirituals, gospels, work songs y blues, en su aspecto técnico, se basa en una continua «conversación»
15

Ibídem, p. 37.

16

Entrevista cit.

17

Ferrer R., Los nudos..., p. 103.

18

Delgado Costa J., "Renée Ferrer con ojos humanos, punto. Dejémonos de hacer tantas distinciones》, en Ferrer R. Los nudos..., cit., p. 219.

19

Ferrer R. Los nudos..., cit., p. 26.

20

Ibídem, p. 44.

21

Ibídem, p. 170.

22

Ibídem, p. 46.

El elemento musical en la obra de Renée Ferrer

MARÍA GABRIELLA DIONISI 
Peiró J. V., «Erotismo y escritura antiautoritaria en Los nudos del silencio de Renée Ferrer» en Ferrer R., Los nudos..., cit. p. 264.

\section{5}

Cortázar J., Las armas secrelas, Madrid, Catedra, 1989, p. 167.

\section{6}

Ferrer R. «La colección de relojes», en La seca y otros cuentos, Asunción, El Lecior, 1986, p. 114.

27 Ibídem, p. 125.
El elemento musical en la obra de Renée Ferrer

MARÍA GABRIELLA DIONISI entre los músicos. Ésta se concretiza en una llamada y una respuesta (call and response) entre las voces instrumentales solistas y el grupo orquestral.

De la misma manera, Renée Ferrer presenta este continuo intercambio entre el saxo-solista y los otros personajes. El saxo llama, convoca, ellos responden: «Un arrebato de notas se interna en la carne. Largas, largas notas penetran en la carne. Sinuosas, lentas, se introducen. Retorcidas, demoradas, dolorosas, se quedan en la sangre. Marea que golpea las paredes del alma. Oleaje desplomándose sobre arrecifes negros. El saxo ha dejado de ser un cuerno de bronce con llaves que unos dedos anónimos presionan, para volverse un hechicero de recuerdos y de olvidos superpuestos, que al conjuro de su pulso se descubren ${ }^{23}$.

De esta forma los tres personajes de la novela, al compás del ritmo del saxo, convertido por fin en «un elemento definidor del erotismo distinto, de liberador del autoritarismo y del miedo reprimido ${ }^{24}$, dejan que sus pensamientos, sus deseos reprimidos, sus esperanzas salgan a la luz, rompiendo el silencio con su nueva voz.

Imposible, a este punto, no pensar en El perseguidor de Julio Cortázar, que forma parte de la colección Las armas secretas de 1959. Aquí también el papel del saxo es fundamental, al estar inspirado el cuento en la vida del jazzman Charlie Parker. Pero, en este caso, el propósito del autor es más bien metafísico. A pesar de que Johnny, el genial saxofonista drogadicto, cuente con su música "para explorarse, para morder con la realidad que se le escapa todo los días» ${ }^{25}$, él trata sobre todo de encontrar, a través de ella, la manera para superar el tiempo físico, evadirse de él y llegar al absoluto.

El interés de Renée Ferrer por las posibilidades de una estrecha interrelación entre la música y la escritura no se acaba con esta novela, por el contrario se profundiza aún más en la reciente realización de una versión teatral del homónimo cuento, La colección de relojes, incluido en su primera colección La seca y otros cuentos de 1986.

Este último se coloca en el ámbito de una narración en equilibrio entre real e irreal, entre lo cotidiano y lo fantástico gracias a la presencia de un relato concreto (el recuerdo, por parte del protagonista masculino, pragmático y dominante, de su vida conyugal antes del in- ternamiento de su mujer en un hospital neuropsiquiátrico) y de la descripción de los extraños efectos que se producen cada día en la protagonista al dar los relojes las doce del mediodía.

El elemento distintivo del cuento reside en el contraste entre la imagen pública de Isabel, madre y mujer ejemplar, apasionada de literatura, pintura, música y «mente analítica», y la imagen que de ella se desprende al sentarse al piano, cuando se entrega «a la música, a los Nocturnos de Chopin o las dificultosas Fugas de Bach. Perdía entonces el contacto con la realidad, encontrándose de pronto a trasmano del tiempo, dispersa en el espacio, embriagada y plena. En esos momentos Isabel no era ella, sino música fluyendo sobre el frío marfil del teclado» ${ }^{26}$.

La escisión femenina entre interioridad y exterioridad impuesta, tan analizada en la literatura feminista, en el cuento se resuelve por parte de la protagonista tan pronto como se pone a tocar el piano, única forma de huida de la pesadilla de una vida de soledad y de represión.

Pero este deseo de fuga de la cotidianidad, se ve progresivamente aplastado por otra forma de opresión, de enclaustramiento, la del tiempo, marcado por los relojes antiguos que llenan su casa y que la alejan cada vez más de cualquier ilusión de cambios en su vida futura.

Al sonido del piano se contrapone ahora el tic-tac de los relojes que se convierten en ojos que la controlan, en dedos que presionan su "garganta cortándole la respiración»27.

En la nueva versión teatral de un acto único dividido en doce escenas, Ferrer introduce algunos cambios estructurales que no sólo son el resultado de la necesidad de adaptar el texto a precisas exigencias escénicas, sino que también responden a una renovada voluntad de hacer hincapié mayormente en dos temas sobresalientes para ella: el del tiempo en su sentido metafísico y el de la lucha femenina para su liberación.

A tal fin, añade dos personajes e invierte la perspectiva de análisis: no es el marido el que recuerda, sino Isabel que, gracias a largos monólogos, interrumpidos sólo por breves diálogos con el esposo, la empleada y un desconocido, cuenta sus emociones y otea sus dudas existenciales. Además, se asiste a un aumento del espacio concreto y simbólico asignado a la 
música que no es un escamoteo escénico, sino es, a veces, un elemento de impacto, otras, el eco rezagado de las acciones.

En este caso los cuadros están acompañados por una de las sinfonías 'londinenses' de Joseph Haydn, la número 101, titulada El reloj y compuesta en 1794.

Como en los trabajos anteriores, Renée Ferrer atribuye a la música un papel clave, como elemento técnico que subraya y refuerza la acción, ya que, con gran equilibrio, la autora escoge los pasajes de la obra de Haydn en relación con los estados de ánimo de Isabel.

Las primeras cuatro escenas son introductoras y nos muestran a la protagonista columpiándose entre frívolos pensamientos estéticos y metafísicas consideraciones sobre el tiempo circular y lineal: «Por qué será que nos parece que el tiempo vuela si es una rueda que gira sobre sí misma repitiendo un mismo círculo? [...] El tiempo en línea recta $[\ldots]$ me perturba con su prolongación indefinida huyendo como un tren que se detiene sólo para bajar los muertos» ${ }^{28}$.

Acto seguido, Isabel analiza su relación con el marido, un «desconocido crónico, sumido en las exigencias del poder ${ }^{29}$ y describe su soledad y su refugio en la música, «en un presente perpetuo sin mayores inquisiciones ${ }^{30}$. Hasta este momento la única banda sonora es la progresiva intensificación del tic-tac de un reloj.

A partir de la cuarta escena hasta la novena, empezamos a notar la directa relación entre las acciones y la música de Haydn. EI Adagio introductor del Primer movimiento, titubeante y melindroso, pero al mismo tiempo rico de fermento e impulso, destaca la condición de espera y de indecisión de la protagonista. La misma alternancia entre la Sinfonía tocada al piano y la del tocadiscos que encontramos hasta la sexta escena, muestra una con- dición poco definida. De hecho sólo en la octava escena se concretiza la prohibición de tocar. A este punto la música, que sigue difundiéndose autónomamente, se convierte en elemento de protesta contra cualquier forma de autoritarismo.

Por eso, en la décima escena, cuando las primeras reacciones físicas y mentales salen a la luz, cuando el falso equilibrio se rompe totalmente y la protagonista toma conciencia de su propia condición, los acordes del Andante del Segundo movimiento se sincronizan totalmente con las transformaciones de Isabel, incitándola a dar rienda libre a sus emociones, a sus deseos hasta el enfrentamiento definitivo con el marido en la undécima escena.

La duodécima escena constituye el triunfo del gran final, en el que confluyen todos los momentos-movimientos. Avanzando del Primer al Segundo, hasta dilatarse en el Cuarto, cuando la orquestra al completo hace retumbar su voz, en un clima de fiesta y de alegría, la música e Isabel alcanzan juntas el momento de la liberación total.

Acompañada por el Cuarto movimiento que crece con más intensidad, ella puede afirmar por fin: «Ni las campanadas ni el tiempo pueden hacerme daño; sólo enseñarme los múltiples rostros que se esconden detrás de una mentira existencial. Ahora yo soy dueña de mi propio destino. Yo decido qué camino tomar. Este estado me ha poblado de luz. Con la luz vendrá la libertad y el valor de asumirla» ${ }^{31}$.

Un lector atento puede encontrar muchos otros temas de debate en los textos que hemos analizado en estas páginas. Nuestra «interpretación musical» pretende ser sólamente una muestra de las infinitas potencialidades de la escritura poética de Renée Ferrer que, durante todos estos años de intenso trabajo, ha cnriquecido las letras de Paraguay.
Ferrer R. La colección de relojes, Asunción, Alta Voz, 2001, pp. 13-14.

29

Ibídem, p. 26

30

Ibidem, p. 27.

31

Ibidem p. 70 . 